\title{
XÁC ĐỊNH HÀM LƯỢNG RUTIN TRONG MỘT SỐ CAO DƯợC LIỆu HOA HÒE ĐượC SỬ DỤNG LÀM NGUYỂ LIẾU TRONG CÁC CHẾ PHẨM THỰC PHẨM BẢO VẸ SỨC KHỎE BẰNG PHƯƠNG PHÁP HPLC-UV
}

\section{Nguyễn Thành Đạt, Nguyễn Thị Hồng Hạnh*, Đàm Thị Thu, Chu Thị Thúy, Hoàng Thị Nương}

Trung tâm kiểm nghiệm thuốc, mỹ phẩm, thực phẩm Hà nội

(Ngày đến tòa soạn: 12/7/2019; Ngày sủa bài sau phản biện: 19/8/2019;

Ngày chấp nhận đăng:10/9/2019)

\section{Tóm tắt}

Xác định hàm lượng Rutin trong một số cao dược liệu Hoa hòe được xác định bằng phương pháp HPLC-UV. Điều kiện sắc ký sử dụng cột Agilent Zorbax Eclipse XDB C18 (150x 4,6 mm; $5 \mu \mathrm{m})$, detector quang phổ tử ngoại ở bước sóng $257 \mathrm{~nm}$, pha động: methanol - dung dịch acid acetic 1\% (40: 60, v/v). Phương pháp có khoảng tuyến tính từ 4,97 - 298,47 $\mu \mathrm{g} / \mathrm{ml}$; Giới hạn định lượng $0,205 \mu \mathrm{g} / \mathrm{ml}$; Độ thu hồi từ 99,87\% - 102,3\%. Úng dụng phương pháp xác định hàm lượng Rutin trong các mẫu cao dược liệu Hoa Hòe: 3 mẫu cao chiết bằng cồn $30 \%, 3$ mẫu cao chiết bằng cồn $70 \%, 3$ mẫu cao chiết bằng nước, kết quả hàm lượng Rutin đạt từ 30,14\% - 38,67\%.

Tù khóa: Sophora japonica L. extracts, HPLC, rutin

\section{1. ĐẠT VẤN ĐỀ}

Hòe [Styphnolobium japonicum (L.) Schott, Syn. Sophora japonica L.], họ Đậu (Fabaceae) là loài cây rất phổ biến tại Việt Nam, được trồng ở nhiều nơi nhất là một số tỉnh duyên hải Bắc Bộ như Thái Bình, Nam Định... Theo GS. Đỗ Tất Lợi - tác giả của cuốn sách nổi tiếng "Những cây thuốc và vị thuốc Việt Nam" thành phần chính của Hoa Hòe là Rutin (chiếm khoảng 20\% - 30\%) [1]. Nó có tác dụng làm giảm tính thấm của mao mạch, tăng sức bền của thành mạch, trong y học được ứng dụng để phòng và điều trị nhiều chứng bệnh liên quan đến tổn thương thành mạch như trĩ, chảy máu đáy mắt,... các chứng bệnh có thể dẫn đến tai biến mạch máu như vữa xơ động mạch, rối loạn tuần hoàn, giòn mao mạch,... Đặc biệt, hiện nay tỉ lệ người có nguy cơ mắc và mắc các bệnh này ngày càng gia tăng. Do đó các thực phẩm bảo vệ sức khỏe được sản xuất từ Hoa Hòe ngày càng nhiều trên thị trường. Nguồn nguyên liệu sử dụng là dược liệu hoặc cao chiết cồn, cao chiết nước từ dược liệu Hoa Hòe. Tuy nhiên hiện nay các loại cao được chiết xuất từ dược liệu Hoa Hòe còn chưa được chuẩn hóa. Đã có một số phương pháp được công bố cho việc xác định hàm lượng Rutin như phương pháp quang phổ hấp thụ UV-Vis [2,6], phương pháp sắc ký lỏng hiệu năng cao [3,4,5,8], sắc ký lỏng khối phổ [7]. Trong đó phương pháp sắc ký lỏng hiệu năng cao là phổ biến nhất bởi có độ nhạy, độ chính xác cao, phù hợp với điều kiện của nhiều phòng thí nghiệm. Do đó nhóm nghiên cứu tiến hành thực nghiệm khảo sát hàm lượng Rutin trong một số mẫu cao dược liệu Hoa Hòe (cao được chiết bằng các dung môi hoặc tỷ lệ dung môi khác nhau) bằng phương pháp sắc ký lỏng hiệu năng cao.

\footnotetext{
*Tel:0912621146 Email: hanhlafon@gmail.com
} 


\section{THƯंC NGHIÊM}

\subsection{Thiết bị, dụng cụ và hóa chất}

\subsubsection{Thiết bị và dụng cu}

Đã được hiệu chuẩn theo ISO/IEC 17025 và GLP, gồm:

- Thiết bị: Hệ thống sắc ký lỏng Shimadzu - LC - 2030C 3D Plus (Nhật) với detector UV- Vis.

- Cân phân tích Sartorius CP224S, độ chính xác d =0,1 mg.

- Máy lắc siêu âm.

- Các dụng cụ thủy tinh cần thiết.

\subsubsection{Hóa chất, chất chuẩn}

- Chất chuẩn: Chuẩn đối chiếu Rutin của Viện Kiểm nghiệm Thuốc TW.

- Dung môi, hóa chất: Methanol, acid acetic đạt tiêu chuẩn tinh khiết dùng cho phân tích hoặc cho HPLC.

\subsection{Mẫu nghiên cứu}

- Mẫu thử: Cao khô được chiết từ dược liệu Hoa Hòe (có hàm lượng rutin là 22,7\%) bằng các loại dung môi khác nhau. Gồm: Cao khô Hoa Hòe chiết bằng nước (10:1); Cao khô Hoa Hòe chiết bằng cồn $70 \%(2: 1)$; Cao khô Hoa Hòe chiết bằng cồn $30 \%(2: 1)$.

- Mẫu trắng: Methanol.

\subsection{Phương pháp nghiên cứu}

\subsection{1. Điều kiện sắc ký}

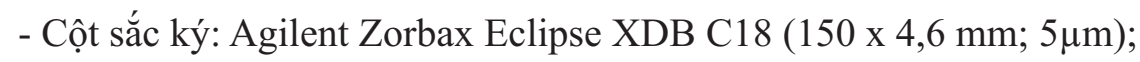

- Nhiệt độ cột: $40^{\circ} \mathrm{C}$;

- Pha động: Methanol - Dung dịch acid acetic 1\% (40:60, v/v);

- Tốc độ dòng: 1,0ml/phút;

- Detector: UV- Vis $257 \mathrm{~nm}$;

- Thể tích tiêm: $10 \mu \mathrm{l}$.

\subsubsection{Chuẩn bị các dung dịch chuẩn và thử}

- Dung dịch chuẩn: Pha chuẩn rutin trong methanol được dãy chuẩn có khoảng nồng độ làm việc: $5 \mu \mathrm{g} / \mathrm{ml} ; 50 \mu \mathrm{g} / \mathrm{ml} ; 100 \mu \mathrm{g} / \mathrm{ml} ; 200 \mu \mathrm{g} / \mathrm{ml} ; 300 \mu \mathrm{g} / \mathrm{ml}$. Lọc qua màng lọc $0,45 \mu \mathrm{m}$.

- Dung dịch thử: Cân chính xác khoảng $0,15 \mathrm{~g}$ mẫu thử, cho vào bình định mức $50 \mathrm{ml}$. Thêm khoảng $30 \mathrm{ml}$ methanol, rung siêu âm trong 15 phút, thêm methanol vừa đủ đến vạch, lắc đều. Hút chính xác 2,0 $\mathrm{ml}$ dịch lọc vào bình định mức $10 \mathrm{ml}$, thêm methanol vừa đủ đến vạch lắc đều. Lọc qua màng lọc $0,45 \mu \mathrm{m}$.

\subsubsection{Phương pháp tính kết quả}

Xác định nồng độ Rutin có trong các mẫu thử dựa vào diện tích pic của Rutin thu được từ sắc đồ của mẫu thử và đường chuẩn biểu thị mối tương quan giữa nồng độ rutin có trong các mẫu chuẩn với diện tích pic tương ứng của mẫu chuẩn.

\section{KẾT QUẢ VÀ BÀN LUẬN}

\section{1. Độ đặc hiệu}

Tiến hành phân tích các mẫu trắng và mẫu đối chiếu chứa rutin theo phương pháp đã xây dựng và ghi lại sắc đồ (Hình 1,2$)$. 


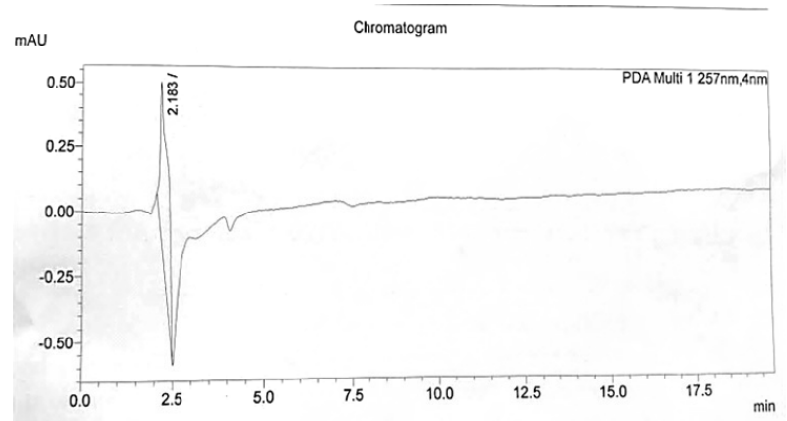

Hình 1. Sắc ký đồ mẫu trắng

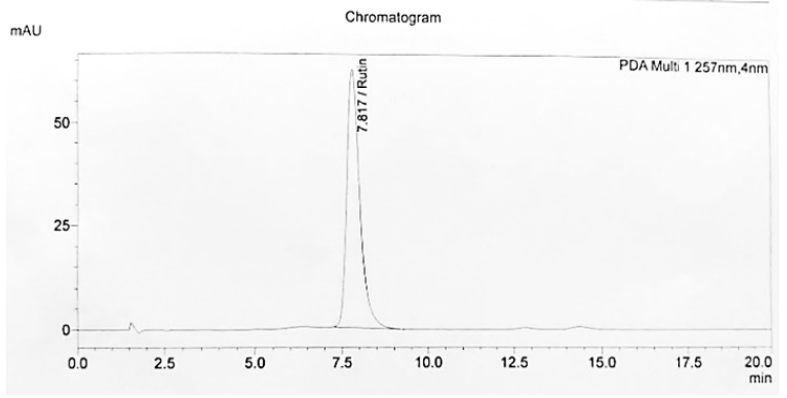

Hình 2. Sắc ký đồ mẫu chuẩn

Trên sắc ký đồ (SKĐ) của mẫu đối chiếu (Hình 2) xuất hiện pic tại các thời điểm 7,8 phút của Rutin. SKĐ của mẫu trắng (Hình 1 ) không xuất hiện pic tại thời điểm trên. Do vậy, phương pháp phân tích có độ đặc hiệu chọn lọc với rutin để phân tích các chất này trong chế phẩm.

\section{2. Độ tuyến tính}

Phân tích các mẫu chuẩn có chứa rutin nồng độ khoảng $5 \mu \mathrm{g} / \mathrm{ml}$ đến $300 \mu \mathrm{g} / \mathrm{ml}$ theo quy trình đã xây dựng. Xác định sự tương quan giữa nồng độ Rutin có trong mẫu và diện tích pic tương ứng thu được trên SKĐ bằng phương pháp hồi qui tuyến tính. Kết quả xác định mối tương quan này được trình bày ở Hình 3.

Bảng 1. Kết quả thẩm định khoảng tuyến tính của phuơng pháp

\begin{tabular}{|c|c|c|c|c|c|c|}
\hline \multirow{3}{*}{ Rutin } & Nồng độ $(\mu \mathrm{g} / \mathrm{ml})$ & 4,97 & 49,75 & 99,49 & 149,24 & 298,47 \\
\cline { 2 - 7 } & Diện tích pic & 120763 & 1016397 & 2056283 & 3053984 & 6167973 \\
\cline { 2 - 7 } & \multicolumn{6}{|c|}{ Phương trình hồi quy: $\mathrm{y}=20623,556 \mathrm{x}+319,563 ; \mathrm{R}=1,000$} \\
\hline
\end{tabular}

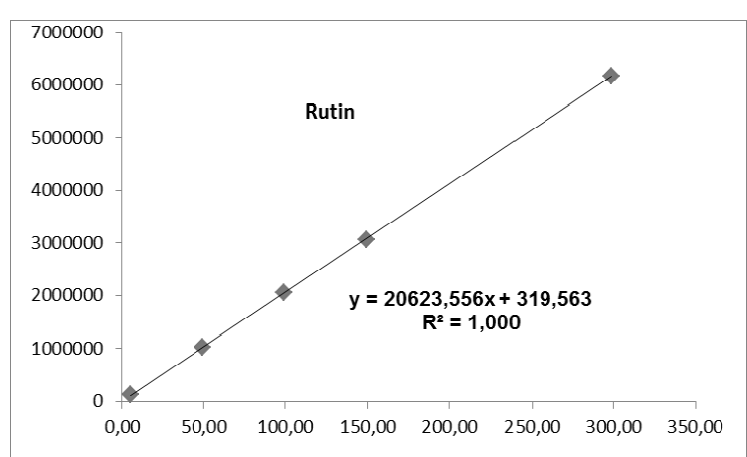

Hình 3. Đồ thị khảo sát sự tuơng quan tuyến tính giữa nồng độ và diện tích pic của rutin

Kết quả cho thấy trong khoảng nồng độ từ 4,97 $\mu \mathrm{g} / \mathrm{ml}$ đến $298,47 \mu \mathrm{g} / \mathrm{ml}$ có sự tương quan tuyến tính giữa nồng độ và diện tích pic với hệ số tương quan $\mathrm{R}=1$. Nồng độ Rutin xác định từ đường chuẩn so với nồng độ lý thuyết đều nằm trong giới hạn cho phép $(80 \%-120 \%)$.

\subsection{Giới hạn định lượng (LOQ)}

Pha loãng dần dung dịch chuẩn Rutin ở mục 2.3.2 đến nồng độ thấp nhất sao cho khi tiêm vào hệ thống sắc ký, tín hiệu thu được cao gấp 10 lần so với nhiễu đường nền và có độ đúng, độ lặp lại đạt yêu cầu để định lượng. Giới hạn định lượng của rutin là $0,205 \mu \mathrm{g} / \mathrm{ml}$.

\section{4. Độ đúng và độ lặp lại}

Tiến hành đánh giá độ đúng, độ lặp lại của phương pháp trên mẫu tự tạo (thêm chuẩn Rutin vào 
nền mẫu placebo) và xử lý theo quy trình phân tích để dung dịch cuối cùng có nồng độ rutin ở 3 mức là $50 \mu \mathrm{g} / \mathrm{ml} ; 100 \mu \mathrm{g} / \mathrm{ml}$ và $200 \mu \mathrm{g} / \mathrm{ml}$. Mỗi mức nồng độ làm 03 mẫu. Xác định hàm lượng Rutin có trong các mẫu bằng đường chuẩn phân tích trong cùng điều kiện. Độ đúng của phương pháp là tỷ lệ \% giữa nồng độ xác định được so với nồng độ lý thuyết. Độ lặp lại của phương pháp được biểu thị bằng giá trị RSD\%. Kết quả xác định độ đúng, độ lặp lại của phương pháp được trình bày ở Bảng 2 .

Bảng 2. Kết quả thẩm định độ đúng, độ lặp lại

\begin{tabular}{|c|c|c|c|}
\hline \multirow{2}{*}{} & \multicolumn{3}{|c|}{ Rutin } \\
\cline { 2 - 4 } & DD1 (49,75 $\boldsymbol{\mu g} / \mathbf{m l})$ & DD2 $(\mathbf{9 9 , 4 9} \boldsymbol{\mu g} / \mathbf{m l})$ & DD3 (198,98 $\boldsymbol{\mu g} / \mathbf{m l})$ \\
\hline Độ thu hồi (\%) & 99,87 & 99,93 & 102,30 \\
\hline Độ lặp lại (RSD \%) & 0,27 & 0,52 & 0,18 \\
\hline Trung bình & \multicolumn{3}{|c|}{$100,7 \%(\mathrm{RSD}=1,38 \%)$} \\
\hline
\end{tabular}

Kết quả thẩm định cho thấy ở các mức nồng độ thấp, trung bình và cao, phương pháp có độ đúng xấp xỉ 100\%; độ lặp lại trong ngày và khác ngày với giá trị RSD nhỏ.

\subsection{Khoảng xác định}

Từ kết quả độ tuyến tính, độ đúng, độ chính xác của phương pháp, khoảng xác định của phương pháp đối với rutin từ $4,97 \mu \mathrm{g} / \mathrm{ml}$ đến $298,47 \mu \mathrm{g} / \mathrm{ml}$.

\subsection{Kết quả phân tích mẫu thực tế}

Sử dụng phương pháp đã xây dựng để xác định hàm lượng của Rutin trong 03 mẫu cao khô Hoa Hòe chiết bằng nước (10:1); 03 mẫu cao khô Hoa Hòe chiết bằng cồn $70 \%(2: 1) ; 03$ mẫu cao khô Hoa Hòe chiết bằng cồn $30 \%(2: 1)$. Kết quả phân tích được trình bày ở Bảng 3 .

Bảng 3. Hàm lượg Rutin (\%) trong chế phẩm

\begin{tabular}{|c|c|c|c|}
\hline Mẫu & Cao chiết nước & Cao chiết cồn $\mathbf{7 0 \%}$ & Cao chiết cồn 30\% \\
\hline 1 & $30,77 \%$ & $37,33 \%$ & $30,40 \%$ \\
\hline 2 & $37,87 \%$ & $36,32 \%$ & $30,14 \%$ \\
\hline 3 & $38,67 \%$ & $37,07 \%$ & $30,74 \%$ \\
\hline
\end{tabular}
$38,67 \%$.

Cao khô dược liệu Hoa Hòe chiết bằng nước (10: 1) hàm lượng rutin đạt từ 30,77\% đến

Cao khô dược liệu Hoa Hòe chiết bằng cồn 30\% (2: 1) hàm lượng rutin đạt từ 30,14\% đến $30,74 \%$.

Cao khô dược liệu Hoa Hòe chiết bằng cồn $70 \%$ (2: 1) hàm lượng rutin đạt từ 36,32\% đến $37,33 \%$.

Kết quả phân tích cho thấy phương pháp có độ chọn lọc và độ tin cậy, phù hợp để ứng dụng trong công tác tiêu chuẩn hóa các mẫu cao dược liệu Hoa Hòe.

\section{KẾT LUẦN}

Nghiên cứu đã xây dựng được phương pháp định lượng Rutin trong các mẫu cao dược liệu Hoa Hòe bằng phương pháp HPLC. Quy trình xử lý mẫu đơn giản bằng cách hòa tan trong methanol; điều kiện sắc ký: cột sắc ký C18 $(150$ x 4,6 mm; 5 mm), detector UV $257 \mathrm{~nm}$, pha động methanolacid acetic $1 \%(40: 60, \mathrm{v} / \mathrm{v})$, tốc độ dòng $1,0 \mathrm{ml} / \mathrm{phút}$, thể tích tiêm mẫu $10 \mu$ l. Kết quả thẩm định cho thấy, phương pháp có giá trị giới hạn định lượng nhỏ $(0,205 \mu \mathrm{g} / \mathrm{ml})$; khoảng tuyến tính rộng (từ $4,97 \mu \mathrm{g} / \mathrm{ml}$ đến $298,47 \mu \mathrm{g} / \mathrm{ml}$ ); độ đúng dao độngtrong khoảng 99,87\% - 102,30\%; độ lặp lại với 
giá trị RSD\% nhỏ $(0,44 \%$ - 1,44\%), đáp ứng yêu cầu đối với phương pháp phân tích hóa học theo AOAC. Phương pháp đã thẩm định có thể ứng dụng định lượng rutin trong các cao dược liệu Hoa Hòe. Kết quả này là thông tin hữu ích để các cơ sở sản xuất tham khảo áp dụng chuẩn hóa bán thành phẩm cao dược liệu Hoa Hòe.

\section{TÀI LIÊU THAM KHẢO}

1. Đỗ Tất Lợi (2006), Những cây thuốc và vị thuốc Việt Nam, Nhà xuất bản Y học, trang 298

2. Dược điển Việt Nam lần xuất bản thứ năm (2017), Nhà xuất bản Y học, tập 2, trang 1195.

3. Bùi Thị Hằng (1990), Nghiên cứu định lượng rutin trong nụ hòe, Tạp chí Dược liệu số 1 , trang $17-20$.

4. Nguyễn Thị Phương Thảo, Trịnh Văn Lẩu (2005), Góp phần nghiên cứu định lượng rutin trong hòe bằng phương pháp HPLC, Tạp chí Kiểm nghiệm thuốc Số 1 , trang15 - 18.

5. Pharmacopoeia of the People's Republic of China, Vol. Ia. (2015). Pharmacopoeia Commission of PRC, pp. $436-437$.

6. H. Xu, Y. Li, H.-W. Tang, C.-M.Liu, and Q.-S. Wu, (2010), "Determination of rutin with $\mathrm{UV}$-Vis spectrophotometric and laser-induced fluorimetric detections using a non-scanning spectrometer", Analytical Letters, Vol. 43, No. 6, pp. 893-904.

7. Chang, L.; Zhang, X.X.; Ren, Y.P.; Cao, L.; Zhi, X.R.; Zhang, L.T. (2013), "Simultaneous Quantification of Six Major Flavonoids From Fructus sophorae by LC-ESI-MS/MS and Statistical Analysis", Indian Journal of Pharmaceutical Sciences. 75 (3), pp. 330 - 338.

8. Kuntić V1, Pejić N, Ivković B, Vujić Z, Ilić K, Mićić S, Vukojević V. (2007), "Isocratic RP-HPLC method for rutin determination in solid oral dosage forms", J Pharm Biomed Anal, 17: 43(2), pp. $718-721$.

9. M. Karthick and P. S. M. Prince (2006), "Preventive effect of rutin, a bioflavonoid, on lipid peroxides and antioxidants in isoproterenol-induced myocardial infarction in rats", Journal of Pharmacy and Pharmacology, Vol. 58, No. 5, pp. 701-707.

10. M. Nassiri-Asl, T. Naserpour Farivar, E. Abbasi et al (2013), "Effects of rutin on oxidative stress in mice with kainic acid-induced seizure", Journal of Integrative Medicine, Vol. 11, No. 5, pp. 337-342.

\section{Summary}

\section{DETERMINATION OF RUTIN CONTENT IN SOPHORA JAPONIA L. EXTRACTS USED AS RAW MATERIAL IN SUPPLEMENTS BY HIGH PERFORMANCE LIQUID CHROMATOGRAPHY}

\section{Nguyen Thanh Dat, Nguyen Thi Hong Hanh, Dam Thi Thu, Chu Thi Thuy, Hoang Thi Nuong}

Hanoi Drugs, Cosmetics, Food Quality Control Center

An HPLC-UV method was proposed in order to determine Rutin in Sophora japonica $L$. extract samples (3 samples extracted with 30\% ethanol, 3 samples extracted with $70 \%$ ethanol and 3 samples extracted with water). The chromatographic conditions were: Agilent Zorbax Eclipse XDB C18 Column ( 150 x $4.6 \mathrm{~mm}, 5 \mu \mathrm{m})$; UV-Vis detector $(257 \mathrm{~nm})$; mobile phase: a mixture of methanol and $1 \%$ acetic acid solution $(40: 60, \mathrm{v} / \mathrm{v})$. The linear range was of 4.97 $298.47 \mu \mathrm{g} / \mathrm{mL}$; the LOQ was of $0.205 \mu \mathrm{g} / \mathrm{mL}$ and the accuracy was within $99.87 \%-102.3 \%$. The method was proved to be suitable for the determination of Rutin in Sophora japonica L. extracts. Rutin content in samples varied from $30.14 \%$ to $38.67 \%$.

Keyword: Sophora japonica L. extracts,HPLC, Rutin. 